\title{
Mucoepidermoid Carcinoma of the Thymus : A Case Report
}

\begin{abstract}
Mucoepidermoid carcinoma of the thymus is an extremely rare malignant mediastinal neoplasm, and to our knowledge, only 13 cases have been reported. We report a case of mucoepidermoid carcinoma of the thymus that was seen in a 53-yr-old man with right chest pain. Chest CT scan showed a huge, cystic mass having a focal solid portion with direct invasion of the adjacent anterior chest wall and pericardium in the anterior mediastinum. Mucoepidermoid carcinoma of the thymus should be included in the differential diagnosis for masses of the anterior mediastinum associated with extensive cystic changes, although the carcinoma is exceedingly rare.
\end{abstract}

Key Words : Mediastinal Neoplasms; Thymus Neoplasms; Carcinoma, Mucoepidermoid

\section{Gang-Deuk Kim, Hye-Won Kim, Jung-Taek Oh*, Hyang-Jeong $\mathrm{JO}^{\dagger}$, Seon-Kwan Juhng}

Department of Diagnostic Radiology and General Surgery*, Wonkwang University School of Medicine, Iksan; Department of Pathology ${ }^{\dagger}$, Gunsan Medial Center, Gunsan, Korea

Received : 7 July 2003

Accepted : 2 September 2003

\section{Address for correspondence}

Seon-Kwan Juhng, M.D.

Department of Diagnostic Radiology, Wonkwang

University Hospital, 344-2 Shinyong-dong, lksan 570-711, Korea

Tel : +82.63-850-1514, Fax : +82.63-851-4749

E-mail : juhngsk@wonkwang.ac.kr

*This paper was supported by Wonkwang University in 2002.

\section{INTRODUCTION}

Thymic carcinomas are unusual malignant neoplasms that have wide variety of morphologic appearances. Mucoepidermoid carcinomas of the thymus are extremely rare malignant mediastinal neoplasms and account for $2 \%$ of thymic carcinomas $(1,2)$. Until now, radiologic reports of mucoepidermoid carcinoma of the thymus have been rare, but the described gross findings are multilocular cystic structures with focal areas of induration within the walls of the cyst or well-circumscribed homogeneous tumor masses (3). We report a case of mucoepidermoid carcinoma of the thymus with radiologic and histologic findings.

\section{CASE REPORT}

A 53-yr-old male was admitted to our hospital complaining of right chest pain. The physical examination and laboratory studies were unremarkable.

Erect posteroanterior and lateral radiographs of the chest showed a well marginated anterior mediastinal mass in the entire right lung zone, compressing the lower trachea, right bronchus, and heart toward the left side (Fig. 1). CT scan of the chest demonstrated a $20 \times 16 \times 10 \mathrm{~cm}$-sized, cystic mass with focal heterogeneously enhanced solid portion anterome- dially in the anterior mediastinum. Direct invasion of the anterior chest wall and pericardium by the mass was suggested, because pericardial fat plane was obliterated and the margin between the mass and the adjacent right anterior chest wall and pericardium was indistinct (Fig. 2). Minimal amount of right pleural effusion and pericardial effusion were associated.

At surgery, after aspiration of fluid within the cystic mass, pericardial invasion was noted. Thus, partial resection of the mass was done. Histologically, squamoid tumor cells formed cords or solid sheets within the fibrous stroma admixed with mucin-secreting epithelium lining gland-like spaces (Fig. 3). The final pathologic diagnosis was poorly differentiated mucoepidermoid carcinoma of the thymus. The patient died in one year after surgery despite postoperative radiation therapy.

\section{DISCUSSION}

The thymic carcinomas are a heterogeneous group of aggressive epithelial malignancies that have a strong propensity for early local invasion and wide spread metastases. Squamous cell carcinoma and lymphoepithelioma-like carcinoma are the most common cell types and usually occur in middle-aged men with a mean age of $46 \mathrm{yr}$ (4-6). Radiologically, thymic carcinomas commonly manifest as large, poorly defined, infiltrative anterior mediastinal masses and associated with areas 
of necrosis, hemorrhage, calcification, or cyst formation (2, 6, 7).

Mucoepidermoid carcinoma was first recognized as a distinct pathologic entity in salivary glands by Stewart et al. in 1945. Since then, this tumor has been identified in several other organs, including lung, esophagus, anus, cervix, and skin. Although extremely rare, mucoepidermoid carcinomas of the thymus have also been described (3). So far, only thirteen cases have been reported in the English literature (3, 8, 9). The patients ranged in age from 17 to $66 \mathrm{yr}$, with a mean age of $35 \mathrm{yr}$ on reported cases (3). Clinically, most patients were asymptomatic or had symptoms of chest discomfort, retrosternal pain and dyspnea.

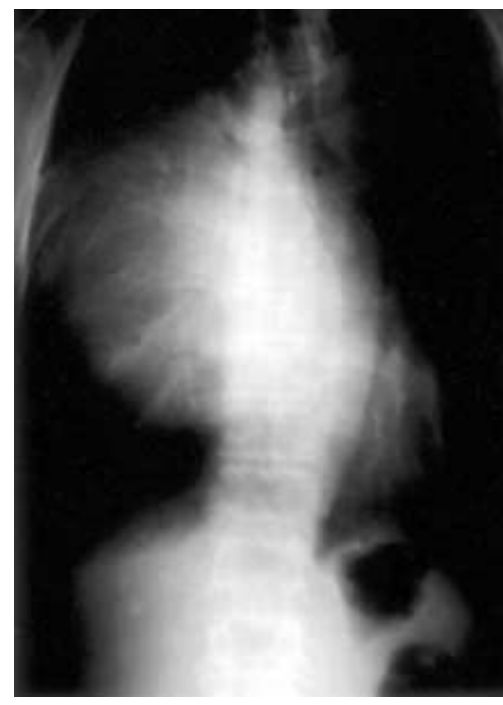

Fig. 1. PA radiographs of the chest shows a huge, well marginated, homogeneous mass in the anterior mediastinum displacing the lower trachea, bronchus and heart contralaterally.
Radiologic reports of mucoepidermoid carcinoma of the thymus were rare. But two distinct gross findings, as described by Moran et al., are multilocular cystic structures varying in size with focal areas of induration within the walls of the cyst and well-circumscribed, homogeneous tumor masses (3). Our case presented as a $20 \mathrm{~cm}$-sized, cystic mass with focal hetero-

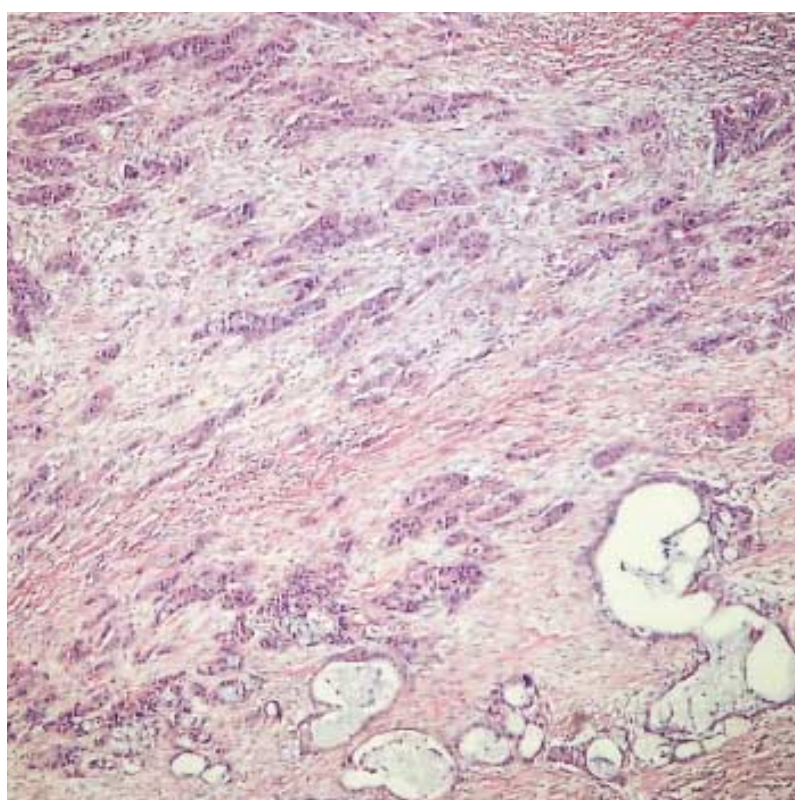

Fig. 3. Photomicrograph $(\mathrm{H}-\mathrm{E}$ stain, $\times 40)$ shows tumor cells forming cords or solid sheets within the fibrous stroma. Three cellular compositions; intermediate, squamous, and mucous cells are noted. Small spaces filled with mucus are also present.
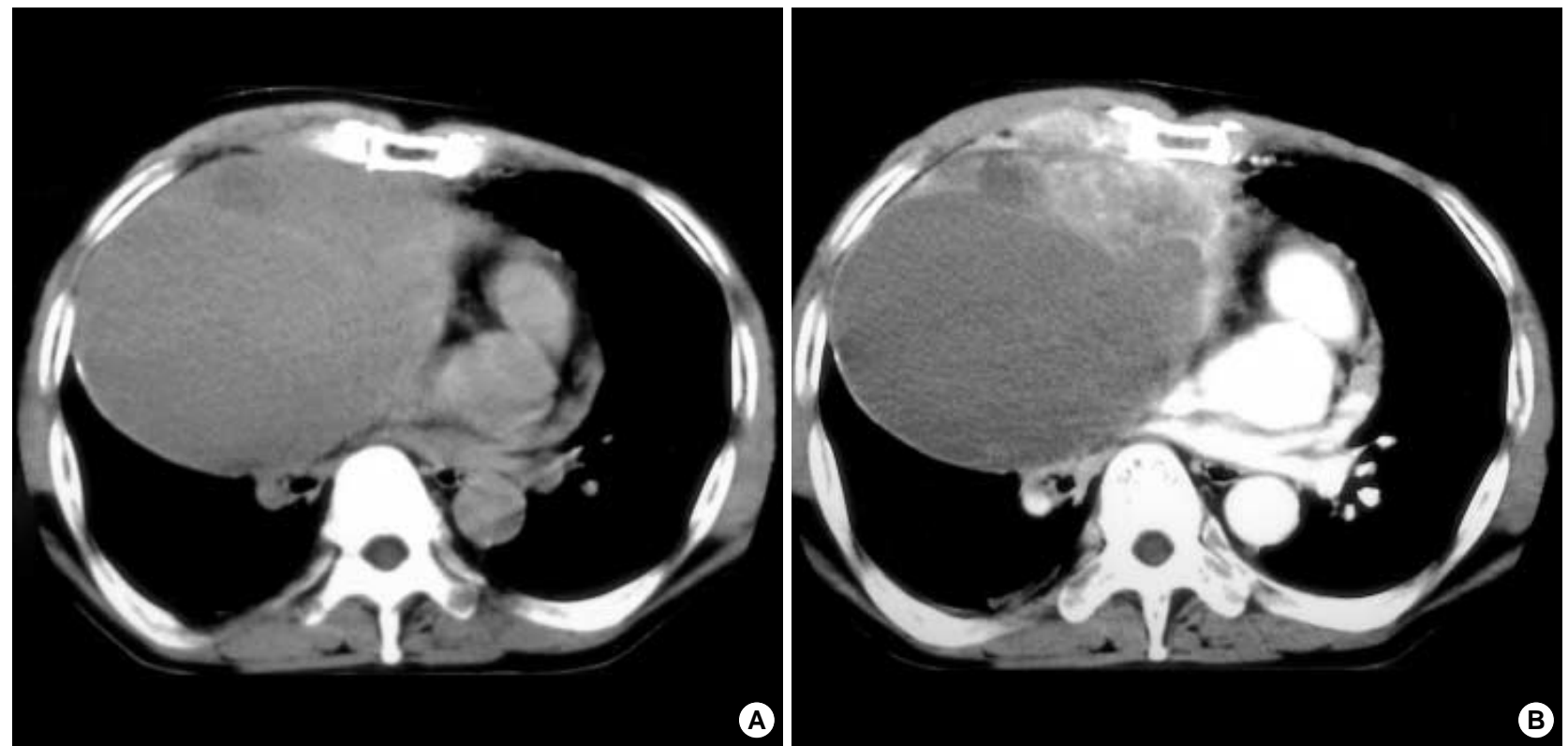

Fig. 2. (A) Chest CT scan at the level of aortic origin demonstrates a huge, low attenuating, cystic mass in anterior mediastinum with internal septa and heterogeneous solid area anteromedially. (B) Contrast enhanced CT scan shows the focal solid mass area with heterogeneous enhancement anteromedially and irregular margin between the mass and anterior chest wall and pericardium. 
geneously enhanced solid portion anteromedially in the anterior mediastinum. The invasion of anterior chest wall and pericardium was suspected due to indistinct margin between the mass and adjacent right anterior chest wall and pericardium, and surgically proved.

Histologically, the lesions showed a spectrum of features that ranged from those of well-differentiated, to moderately well-differentiated, to poorly differentiated mucoepidermoid carcinoma, with sheets and solid islands of squamoid cells admixed with mucin-secreting epithelium lining gland-like spaces (3). The histogenesis of these tumors is still unclear; however, the demonstration of transitions between the tumor cells and the epithelium lining the cysts as well as residual non-neoplastic thymic remnants within the walls of the cysts in four of six cases supports the theory that these tumors arise from thymic epithelium (3).

Differential diagnoses of masses of the anterior mediastinum associated with extensive cystic changes include thymic cysts, thymomas, teratomas, seminomas, Hodgkin's disease, and metastasis (10-14). And also mucoepidermoid carcinoma of the thymus should be included in the differential diagnosis, although the carcinoma is an exceedingly rare anterior mediastinal malignant tumor (3). It is very difficult to differentiate from each other by only radiologic findings (10-14). However, mucoepidermoid carcinoma of the thymus should be considered when a large cystic mass with focal induration within the anterior mediastinum on CT scan is noted.

\section{REFERENCES}

1. Suster S, Rosai J. Thymic carcinoma: a clinicopathologic study of 60 cases. Cancer 1991; 67: 1025-32.

2. Jung KJ, Lee KS, Han JH, Kim JG, Kim TS, Kim EA. Malignant thymic epithelial tumors: CT-pathologic correlation. Am J Roentgenol
2001; 176: 433-9.

3. Moran CA, Suster S. Mucoepidermoid carcinomas of the thymus: a clinicopathologic study of six cases. Am J Surg Pathol 1995; 19: 82634.

4. Ahn JS, Park CK, Park NH, Kim JB, Yoo YS, Lee KS, Choi SY, Kwon YM. Clinical analysis for thymic carcinoma. Korean J Thorac Cardiovasc Surg 2001; 34: 162-6.

5. Joo YD, Kim JH, Sohn CH, Kim RH, Kim CH, Suh HS. Thymic carcinoma; report of eight cases. J Korean Cancer Assoc 1998; 30: 743-51.

6. Strollo DC, Rosado de Christenson ML, Jett JR. Primary mediastinal tumors. Part 1: tumors of the anterior mediastinum. Chest 1997; 112: 511-22.

7. Lee EJ, Juhng GS, Kim SM, Huh JD, Joh YD, Shin MJ, Kim JS, Suh SJ. CT differentiation of invasive thymoma and thymic carcinoma. $J$ Korean Radiol Soc 1998; 39: 941-6.

8. Tanaka M, Shimokawa R, Matsubara O, Aoki N, Kamiyama R, Kasuga T, Hatakeyama S. Mucoepidermoid carcinoma of the thymic region. Acta Pathol Jpn 1982; 32: 703-12.

9. Brightman I, Morgan JA, Kunze WP, Sheppard MN. Primary mисоepidermoid carcinoma of the thymus: a rare cause of mediastinal tumour. Thorac Cardiovasc Surgeon 1992; 40: 90-1.

10. Jeung MY, Gasser B, Gangi A, Bogorin A, Charneau D, Wihlm JM, Dietemann JL, Roy C. Imaging of cystic masses of the mediastinum. Radiographics 2002; 22: S79-93.

11. Brown LR, Aughenbaugh GL. Masses of the anterior mediastinum: CT and MR Imaging. Am J Roentgenol 1991; 157: 1171-80.

12. Song SY, Choi YW, Jeon EY, Jeon SC, Seo HS, Hahm CK. Cystic thymic diseases: CT manifestations. J Korean Radiol Soc 1995; 33: 373-8.

13. Rosado de Christenson ML, Galobardes J, Moran CA. Thymoma: radiologic-pathologic correlation. Radiographics 1992; 12: 151-68.

14. Suster S, Rosai J. Multilocular thymic cyst: an acquired reactive process. Study of 18 cases. Am J Surg Pathol 1991; 15: 388-98. 